\title{
INTRAVENOUS DEXMEDETOMIDINE FOR LABOUR ANALGESIA IN WOMEN WITH PREECLAMPSIA
}

\author{
Nidhi Mishra', Amit Jain², Monica Sharma ${ }^{3}$ \\ ${ }^{1}$ Assistant Professor, Department of Obstetrics and Gynaecology, Bundelkhand Medical College, Sagar, Madhya Pradesh. \\ ${ }^{2}$ Assistant Professor, Department of Anaesthesiology, Bundelkhand Medical College, Sagar, Madhya Pradesh. \\ ${ }^{3}$ Consultant, Obstetrics and Gynaecology, Narayan Hospital, Sagar.
}

ABSTRACT
BACKGROUND
Parenteral opioids and sedatives are the most frequently prescribed agents for women in labour in many poor resource settings.
These have shown poor pain relief and a lot of side effects in both the mother and the foetus. In patients with severe pre-eclampsia
who are already haemodynamically compromised labour pains and delivery can result in haemodynamic instability, which can
compromise both the mother and the neonate. Dexmedetomidine is a highly selective $\alpha-2$ agonist, which when used in recommended
dose in the form of an infusion has several desirable properties like sedation, anxiolysis, sympatholysis, analgesia, decreased
anaesthetic requirements, maintains cardiovascular stability and provides a smooth recovery.

AIM

The aim of this study was to study the haemodynamic effects of intravenous dexmedetomidine when used in patients with severe pre-eclampsia for labour analgesia.

\section{MATERIALS AND METHODS}

The study was conducted in the Department of Obstetrics and Gynaecology of Bundelkhand Medical College, Sagar, between January 2015 and December 2016; 40 labouring patients with severe pre-eclampsia were included in the study; 20 each were allocated to the study and control group. The study group received intravenous Dexmedetomidine in the recommended doses $(1$ $\mathrm{ug} / \mathrm{kg}$ loading dose over 10-15 minutes followed by an infusion at $0.2-0.7 \mathrm{ug} / \mathrm{kg} / \mathrm{hour}$ ) when in active labour, while the control group received Intravenous Fentanyl. The two groups were compared regarding the duration of labour, the mode of delivery, the neonatal outcome, the onset and duration of analgesia and maternal haemodynamic parameters during labour and delivery. The data obtained in this study was tabulated and analysed using the Chi-square test and the $\mathrm{Z}$ test with p value of 0.05 taken as significant.

\section{RESULTS}

It was found out that the group of patients who received Dexmedetomidine were more haemodynamically stable during labour and delivery; there was significant pain relief, shorter duration of labour and better neonatal outcome in comparison to the control group.

\section{CONCLUSION}

From this study we can conclude that although a newer drug Dexmedetomidine can be used for intravenous labour analgesia in patients with severe pre-eclampsia with fewer maternal haemodynamic side effects and better maternal and neonatal outcome in poor resource settings.

\section{KEYWORDS}

Preeclampsia, Labour-Analgesia, Dexmedetomidine, Intravenous, Haemodynamics.

HOW TO CITE THIS ARTICLE: Mishra N, Jain A, Sharma M. Intravenous dexmedetomidine for labour analgesia in women with preeclampsia. J. Evolution Med. Dent. Sci. 2016;5(52):3408-3411, DOI: 10.14260/jemds/2016/787

\section{INTRODUCTION}

Pain during childbirth has been described by women as severe and frequent. Satisfactory analgesia is of paramount importance in labour.[1] Parenteral opioids and sedatives are the most frequently prescribed agents for women in labour in many poor resource settings.[2] Pain relief not only provides patient's comfort, but also attenuates the release of stress hormones, whose actions can draw from the parturients reserves as well as deprive the foetus of oxygen and nutrients. ${ }^{[1]}$

Financial or Other, Competing Interest: None.

Submission 02-05-2016, Peer Review 01-06-2016,

Acceptance 07-06-2016, Published 29-06-2016.

Corresponding Author:

Dr. Nidhi Mishra,

Sewa Hospital,

M.I.G.-39, Padmakarnagar,

Makronia, Sagar-470004,

Madhya Pradesh.

E-mail: drnidhimishra@yahoo.com

DOI: $10.14260 /$ jemds/2016/787
The provision of effective labour analgesia is now known to decrease the inhibitory effects of endogenous maternal catecholamine on uterine contractility, attenuates maternal acidosis and improves intrapartum maternal well-being.

Dexmedetomidine is a highly selective $\alpha-2$ adrenergic receptor agonist which when used in recommended dose in the form of an infusion has several desirable properties like sedation, anxiolysis, sympatholysis, analgesia, stimulation of uterine contractions, decreased intraoperative anaesthetic requirements (Narcotic, inhalational), cardiovascular stability, smooth recovery when used as an adjunct to general anaesthesia and above all preserves respiratory function. It was approved by United States Food and Drug Administration (US FDA) in 1999 for use in humans for short-term sedation and analgesia in Intensive Care Unit (ICU) for less than 24 hours. ${ }^{[3][4]}$

Epidural analgesia is considered the gold standard in the treatment of labour associated pain. However, its use is restricted in patients with contraindications and in those who 
refuse to receive it because of its invasive nature and potential complications. There are several case reports describing successful use of dexmedetomidine in labour analgesia if regional was contraindicated, if patient was not willing for labour epidural or as an adjunct to labour epidural if pain relief was not satisfactory without any adverse fetal outcomes in the recommended doses (1 ug/kg loading dose over 10-15 minutes followed by an infusion at $0.2-0.7 \mathrm{ug} / \mathrm{kg} / \mathrm{hour} .{ }^{[3]}$ Similarly, literature describes that as dexmedetomidine has a high placental retention, it does not cross the placenta to reach the fetus. ${ }^{[4]}$ Epidural analgesia remains the gold standard for labour. ${ }^{[5]}$ But in parturients with cardiac ailments who cannot tolerate haemodynamic disturbance during labour, parturients in whom epidural is contraindicated (Coagulopathy, spinal cord diseases, etc.) or epidural is not effective, dexmedetomidine can be used effectively. Abu-Halawah et al, described the successful use of Intravenous (IV) dexmedetomidine infusion in a pregnant woman with diabetes mellitus and Pregnancy-Induced Hypertension (PIH) who refused labour epidural. LSCS was done under general anaesthesia with dexmedetomidine infusion uneventfully with no untoward maternal and child adverse events (European Journal of Anaesthesiology, 2009).[6] Literature describes that dexmedetomidine has a high placental retention and does not cross the placenta with less incidence of fetal bradycardia.[4]

We hypothesized that dexmedetomidine would be effective in reducing the maternal haemodynamic responses to labour and delivery in pre-eclamptic patients without adverse neonatal effects.

\section{MATERIALS AND METHODS}

After approval by Local Research Ethics Committee, informed consent was obtained from all patients participating in the study. The present study included forty full term parturients aged 20-35 years with preeclampsia. The patients were divided into two groups and they were selected randomly to receive either intravenous fentanyl $1 \mu \mathrm{g} / \mathrm{kg}$ (Control group) or $0.4 \mu \mathrm{g} / \mathrm{kg} / \mathrm{h}$ intravenous dexmedetomidine (Study group) at the start of active labour (Cervical dilatation $3 \mathrm{cms}$ ) and stopped after delivery ( $\mathrm{n}=20$ per group). For randomization, patients drew a sealed opaque envelope from a shuffled deck containing a card representing one of the treatment groups. Patients were not informed of their treatment group. Demographic data of the patients were recorded including the maternal age, parity, body weight, gestational age and birth weight. The exclusion criteria were parturients with any medical illness other than pregnancy induced hypertension (Severe renal, hepatic and cardiac illness, neurological or muscular disease and anaemia), allergy to dexmedetomidine or evidence of any foetal compromise. Monitoring of the patients was done using non-invasive blood pressure measurement and pulse oximetry. After the neonate and placenta were delivered, an infusion of 10 IU oxytocin in 500 ml Ringer lactate solution was given. Changes in maternal heart rate, mean blood pressure and foetal heart sounds were recorded every 15 minutes after the start of the intravenous infusion. The time from start of the intravenous infusion to delivery was also noted. The uterine contraction after placental delivery was assessed by the obstetrician and scored from 0 to 3 according to the Visual Analogue Scale (VAS).[7] as 0 means complete uterine relaxation and 3 refers to best contraction. Apgar score of the neonates was assessed by the paediatrician, also all neonates were observed for respiratory depression and bradycardia during the first hour after delivery.

The data obtained in this study was tabulated and analysed using the Chi-square test and the $\mathrm{Z}$ test with $\mathrm{p}$ value of 0.05 taken as significant.

\section{RESULTS}

The demographic data (Age, weight, gestational age) and the total duration of labour were similar in both groups (Table 1).

On comparing the means of the two groups, the average Heart Rate (HR) and Mean Arterial Blood Pressure (MAP) were the same in both groups. The heart rate in the study group during the entire duration of labour was lower than that in the control group and the difference was proven to be statistically highly significant $(\mathrm{p}=0.001)$.

Onset of analgesia was faster and the duration of analgesia was longer in the study group than the control group and the difference was proven to be statistically highly significant $(p=0.001)$ (Table 2). Patients in the study group had statistically significant lower change in mean arterial blood pressure, while patients in the control group showed much higher mean arterial blood pressure at the time of delivery. This relation was proven to be highly significant, $(\mathrm{p}=0.001)$. Also the dexmedetomidine group showed greater uterine tone immediately after delivery than the fentanyl group. This relation was proven to be highly significant, $(p=0.001)$ (Table 3).

As regards the neonatal parameters, there was not much difference between both groups in Apgar score at 1 and 5 minutes (Table 4).

\begin{tabular}{|c|c|c|}
\hline Characteristics & $\begin{array}{c}\text { Study Group } \\
(\mathbf{n = 2 0 )} \mathbf{( \% )}\end{array}$ & $\begin{array}{c}\text { Control Group } \\
(\mathbf{n}+\mathbf{2 0} \mathbf{( \% )}\end{array}$ \\
\hline Mean age (In years) & $23.20( \pm 3.06)$ & $22.42( \pm 3.06)$ \\
\hline Mean weight (In Kgs) & $62.12( \pm 5.36)$ & $63.35( \pm 6.55)$ \\
\hline Primipara & $14(70)$ & $11(55)$ \\
\hline Multipara & $6(30)$ & $9(45)$ \\
\hline Baseline VAS & $>6$ & $>6$ \\
\hline \multicolumn{2}{|c|}{ Table 1: Maternal Patient Characteristics } \\
\hline
\end{tabular}

VAS: Visual Analogue Score

\begin{tabular}{|c|c|c|c|c|}
\hline Time & $\begin{array}{c}\text { Study Group } \\
(\mathbf{n}=\mathbf{2 0}) \\
\text { Mean } \pm \text { SD }\end{array}$ & $\begin{array}{c}\text { Control } \\
\text { Group } \\
(\mathbf{n}=\mathbf{2 0}) \\
\text { Mean } \pm \text { SD }\end{array}$ & $\mathbf{P}$ & $\begin{array}{c}\text { Signific } \\
\text { ance }\end{array}$ \\
\hline Onset (s) & $52.6 \pm 12.84$ & $73.5 \pm 23.45$ & $<0.001$ & $\begin{array}{c}\text { Signific } \\
\text { ant }\end{array}$ \\
\hline $\begin{array}{c}\text { Maximu } \\
\text { m } \\
\text { analgesia } \\
\text { (s) }\end{array}$ & $232.5 \pm 12.53$ & $145.6 \pm 65.25$ & $<0.001$ & $\begin{array}{c}\text { Signific } \\
\text { ant }\end{array}$ \\
\hline $\begin{array}{c}\text { Duration } \\
\text { of } \\
\text { analgesia } \\
\text { (min) }\end{array}$ & $158.24 \pm 51.2$ & $132.2 \pm 48.92$ & $<0.001$ & $\begin{array}{c}\text { Signific } \\
\text { ant }\end{array}$ \\
\hline \multicolumn{3}{|c|}{ Table 2: Onset, Time to Reach Maximum Analgesia } \\
and Duration of Analgesia
\end{tabular}

SD: Standard Deviation 


\begin{tabular}{|c|c|c|c|c|c|}
\hline VAS During Contractions & $\begin{array}{c}\text { Study Group } \\
(\mathbf{n = 2 0 )}\end{array}$ & $\begin{array}{c}\text { Control Group } \\
(\mathbf{n = 2 0 )}\end{array}$ & Total & $\mathbf{p}$ & Significance \\
\hline $\mathbf{0}$ & $2(10)$ & $10(50)$ & $12(60)$ & $<0.001$ & Significant \\
\hline $\mathbf{1}$ & $6(30)$ & $8(40)$ & $14(70)$ & & \\
\hline $\mathbf{2}$ & $11(55)$ & $2(10)$ & $13(65)$ & & \\
\hline $\mathbf{3}$ & $1(5)$ & $0(0)$ & $1(5)$ & & \\
\hline Total & $20(100)$ & $20(100)$ & $40(100)$ & & \\
\hline
\end{tabular}

VAS: Visual Analogue Score

\begin{tabular}{|c|c|c|c|c|}
\hline $\begin{array}{c}\text { APGAR } \\
\text { Scores }\end{array}$ & $\begin{array}{c}\text { Study } \\
\text { Group } \\
(\mathbf{n = 2 0}) \\
\text { Mean } \pm \text { SD }\end{array}$ & $\begin{array}{c}\text { Control } \\
\text { Group } \\
(\mathbf{n}=\mathbf{2 0}) \\
\text { Mean } \pm \text { SD }\end{array}$ & $\mathbf{p}$ & Significance \\
\hline $\begin{array}{c}\text { APGAR } \\
(1 \text { min) }\end{array}$ & $6.85 \pm 0.80$ & $7.32 \pm 0.81$ & 0.046 & Significant \\
\hline $\begin{array}{c}\text { APGAR } \\
(5 \text { mins })\end{array}$ & $8.29 \pm 0.34$ & $8.82 \pm 0.57$ & 0.480 & $\begin{array}{c}\text { Not } \\
\text { significant }\end{array}$ \\
\hline \multicolumn{5}{|c|}{ Table 4: APGAR Scores } \\
\hline
\end{tabular}

SD: Standard Deviation

\section{DISCUSSION}

Using sedatives and narcotics in a parturient have always been controversial, as these drugs tend to cross the uteroplacental barrier and can have deleterious effects on the baby. But newer drugs like dexmedetomidine due to their different and unique pharmacokinetics do not cross placenta significantly. Dexmedetomidine has a high placental retention $\{0.77$ maternal/foetal index). Also, it is highly lipophilic as a result of which it is retained in placental tissue.[4] Because of these properties, it does not cross the uteroplacental barrier and even if it does cross it is negligible. Also, it increases the frequency and amplitude of uterine contraction directly.[7] There were many case reports of use of dexmedetomidine in parturients after the proof of its retention in the placenta with negligible effect on the foetus. There are several case reports describing successful use of dexmedetomidine in labour analgesia if regional was contraindicated, if patient was not willing for labour epidural or as an adjunct to labour epidural if pain relief was not satisfactory without any adverse foetal outcomes in the recommended doses $(1 \mathrm{ug} / \mathrm{kg}$ loading dose over 10-15 minutes followed by an infusion at 0.2-0.7 $\mathrm{ug} / \mathrm{kg} /$ hour).[3][4]

Epidural analgesia remains the gold standard for labour.[5] But in parturients with cardiac ailments who cannot tolerate haemodynamic disturbance during labour, parturients in whom epidural is contraindicated (Coagulopathy, spinal cord diseases, etc.) or epidural is not effective, dexmedetomidine can be used. Abu-Halawah et al, described the successful use of Intravenous (IV) dexmedetomidine infusion in a pregnant women with diabetes mellitus and Pregnancy-Induced Hypertension (PIH) who refused labour epidural. LSCS was done under general anaesthesia with dexmedetomidine infusion uneventfully with no untoward maternal and child adverse events (European Journal of Anaesthesiology, 2009).[6] Palanisamy et al, published a case report in International Journal of Obstetric Anaesthesia, 2012 regarding use of dexmedetomidine in a 31-year-old parturient with spinabifida occulta with a tethered spinal cord reaching L5-S1 who was on Fentanyl Intravenous Patient Controlled Analgesia (IVPCA) for labour analgesia, which was not helping her. She was administered general anaesthesia for prolonged first stage of labour and suspected chorioamnionitis with dexmedetomidine infusion on flow. A healthy baby was delivered with normal Apgar scores and no deficits. ${ }^{[8]}$ Juliana Maria Mendoza Villa published two case reports in Rev Colomb Anaesthesiol, 2012 where dexmedetomidine was used as an adjunct for labour analgesia along with remifentanil. Both patients underwent vaginal delivery, although the first patient had instrumentation. Babies were delivered with normal Apgar scores at 1 and 5 minutes.[9] Alex T. Sia and Ban L. Sng in their editorial in International Journal of Obstetric Anaesthesia, mentioned that dexmedetomidine if used in a properly, selected parturient can provide sedation and haemodynamic stability with minimal risk of respiratory depression.[10]

In maternal conditions like Pulmonary Hypertension (Primary/acquired), PIH, Rheumatic Heart Disease (Especially mitral Stenosis), Thyrotoxicosis and Coronary artery disease where haemodynamic fluctuations during labour or caesarean section can be disastrous, dexmedetomidine can be used in recommended doses due to its desirable properties of analgesia, sedation, sympatholysis and ability to reduce anaesthetic requirement. Most of the case reports that described the use of dexmedetomidine in parturients have mentioned that babies delivered were with normal Apgar scores, which proves that even if there is any uteroplacental transfer, it does not affect the foetal well-being. However, caution has to be taken while using dexmedetomidine in presence of bradyarrhythmias, severe left ventricular or biventricular dysfunction and in volume depleted patients. Also, use of dexmedetomidine requires dose adjustment in presence of hepatic or renal dysfunction. In this study, we tried to get benefit from cardiovascular stabilizing effect of dexmedetomidine to use it in preeclamptic patients and we randomly took forty patients with preeclampsia in active labour, twenty were given dexmedetomidine intravenously and the other twenty were given fentanyl for labour analgesia. Comparing our results with the control group result (fentanyl group), the infusion of dexmedetomidine in a rate $0.4 \mu \mathrm{g} / \mathrm{kg} / \mathrm{h}$ showed a significant slowing in heart rate and lowering of the mean arterial blood pressure during labour and delivery in preeclamptic patients, also it was noticed that babies were delivered with normal Apgar score. Our results were in fact comparable to a previous study carried out by Abu-Halaweh et al[6] who reported on the successful use of intravenous dexmedetomidine infusion in pregnant women with diabetes mellitus and pregnancy-induced hypertension under general anaesthesia without any untoward maternal and child adverse events.

The limitation of this study is that we studied the effect of dexmedetomidine in only a single dose and we did not study the effect of increasing the dose on the haemodynamic 
parameters, as it is known that the effect of dexmedetomidine on blood pressure and heart rate is dose dependent.[11]

The other limitation is that although the cases were randomly allocated into 2 groups, it was not a blinded study to the demonstrators.

\section{CONCLUSION}

Parturients especially those in the developing countries have few or no options for labour pain relief during childbirth. Epidural analgesia is the most effective method for pain relief during labour.[2] However, it may not be the best option for women with a contraindication. Alternative strategies for pain relief may be necessary. Parenteral opioids and sedatives are the most frequently prescribed agents for women in labour in many poor resource settings.[2] They have been shown to have little or no effect on labour pain and their use is accompanied with maternal and neonatal side effects.[2] Studies have shown that when used for labour analgesia, dexmedetomidine is retained in the placental tissue owing to its lipophilicity resulting in decreased transfer to the foetus leading to less chances of foetal bradycardia. Its use has been studied in parturients with failed epidural analgesia along with systemic opioids with a resultant good maternal anxiolysis, haemodynamic stability and stimulation of uterine contractions.[5]

It could be concluded that this study proved the effective use of dexmedetomidine in preeclamptic patients for labour analgesia, as it stabilizes the maternal haemodynamic parameters with negligible effect on the foetus.

With vigilant monitoring of haemodynamics and proper selection of patient, dexmedetomidine may be used in a parturient having medical conditions in which tachycardia and hypertension is not desirable. Literature suggests that dexmedetomidine does not cross uteroplacental barrier due to its high placental extraction.[5][11] One should try to avoid the use of dexmedetomidine in presence of bradyarrhythmias, severe left ventricular/biventricular dysfunction and hypovolemic states. Dose adjustment is required as recommended in presence of hepatic and renal dysfunction. ${ }^{[12]}$

\section{REFERENCES}

1. Halpern SH, Muir H, Breen TW, et al. A mulitcenter randomized controlled trial comparing patient-controlled epidural with intravenous analgesia for pain relief in labour. Anaesth Analg 2004;99(5):1532-8.
2. Mordani K, Macarthur A. Anaesthesia considerations of preeclamptic patients. In: Baker PN, Kingdom JCP, ed. Preeclampsia: current perspectives on managements. New York: Parthenon Publishing 2004:196-9.

3. Kaur M, Singh PM. Current role of dexmedetomidine in clinical anaesthesia and intensive care. Anaesth Essays Res 2011;5(2):128-33.

4. Grewal A. Dexmedetomidine: new avenues. J Anaesthesiol Clin Pharmacol 2011;27(3):297-302.

5. Ghaly RG, Flynn RJ, Moore J. Isoflurane as an alternative to halothane for caesarean section. Anaesthesia 1988;43(1):5-7.

6. Abu-Halaweh SA, Al Oweidi AK, Abu-Malooh $\mathrm{H}$, et al. Intravenous dexmedetomidine infusion for labour analgesia in patient with preeclampsia. Eur J Anaesthesiol 2009;26(1):86-7.

7. Karaman S, Evren V, Firat V, et al. The effects of dexmedetomidine on spontaneous contractions of isolated gravid rat myometrium. Adv Ther 2006;23(2):238-43.

8. Palanisamy A, Klickovich RJ, Ramsay M, et al. Intravenous dexmedetomidine as an adjunct for labour analgesia and caesarean delivery anaesthesia in a parturient with a tethered spinal cord. Int J Obstet Anaesth 2009;18(3):258-61.

9. Villa JMM. Dexmedetomidine as adjuvant for analgesia in labour: report of two cases. Rev Colomb Anaestesiol 2012;40(1):79-81.

10. Nair AS, Sriprakash K. Dexmedetomidine in pregnancy: review of literature and possible use. J Obstet Anaesth Crit Care 2013;3:3-6.

11. Toyoma H, Wagatsuma T, Ejima Y, et al. Caesarean section and primary pulmonary hypertension: the role of intravenous dexmedetomidine. Int J Obstet Anaesth 2009;18(3):262-7.

12. Grosu I, Lavand'homme P. Use of dexmedetomidine for pain control. F1000 Med Rep 2010;2:90. 